\title{
Projecting Future Climate Change Scenarios Using Three Bias-Correction Methods
}

\author{
Donghyuk Kum, ${ }^{1}$ Kyoung Jae Lim, ${ }^{1}$ Chun Hwa Jang, ${ }^{1}$ Jichul Ryu, ${ }^{2}$ Jae E. Yang, \\ Seong Joon Kim, ${ }^{4}$ Dong Soo Kong, ${ }^{5}$ and Younghun Jung ${ }^{1}$ \\ ${ }^{1}$ Department of Regional Infrastructure Engineering, Kangwon National University, Chuncheon, Gangwon 200-701, Republic of Korea \\ ${ }^{2}$ National Institute of Environmental Research, Incheon 404-708, Republic of Korea \\ ${ }^{3}$ Department of Biological Environment, Kangwon National University, Chuncheon, Gangwon 200-701, Republic of Korea \\ ${ }^{4}$ Department of Civil \& Environmental System Engineering, Konkuk University, Seoul 143-701, Republic of Korea \\ ${ }^{5}$ Department of Life Science, Kyonggi University, Suwon 443-760, Republic of Korea
}

Correspondence should be addressed to Younghun Jung; jung.younghun@gmail.com

Received 22 August 2014; Revised 8 November 2014; Accepted 25 November 2014; Published 14 December 2014

Academic Editor: Klaus Dethloff

Copyright (C) 2014 Donghyuk Kum et al. This is an open access article distributed under the Creative Commons Attribution License, which permits unrestricted use, distribution, and reproduction in any medium, provided the original work is properly cited.

\begin{abstract}
We performed bias correction in future climate change scenarios to provide better accuracy of models through adaptation to future climate change. The proposed combination of the change factor (CF) and quantile mapping (QM) methods combines the individual advantages of both methods for adjusting the bias in global circulation models (GCMs) and regional circulation models (RCMs). We selected a study site in Songwol-dong, Seoul, Republic of Korea, to test and assess our proposed method. Our results show that the combined CF + QM method delivers better performance in terms of correcting the bias in GCMs/RCMs than when both methods are applied individually. In particular, our proposed method considerably improved the bias-corrected precipitation by capturing both the high peaks and amounts of precipitation as compared to that from the CF-only and QM-only methods. Thus, our proposed method can provide high-accuracy bias-corrected precipitation data, which could prove to be highly useful in interdisciplinary studies across the world.
\end{abstract}

\section{Introduction}

With the increase in industrialization around the world, the quality of human life has improved in various aspects through advancement in scientific technology, professionalism in occupations, level of consumption, and so forth. However, these improvements have caused an excessive use of fossil fuels (coal, petroleum, natural gas, etc.) [1] and an increase in global temperatures triggered by the increase in greenhouse gases (carbon dioxide, nitrogen dioxide, etc.) in the troposphere [2].

In general, human activity in agriculture, industry, and commerce influences global ecosystems through factors such as aerosol effects, land use change, and deforestation. This can lead to negative impacts such as increase in air temperature and changes in precipitation patterns [3], which mainly influence climate change globally [4]. According to the 4th Assessment Report (AR4), Intergovernmental Panel on Climate Change (IPCC) [5], the number of days with precipitation and flood occurrence frequencies has steadily and gradually increased due to unusual climate changes indicating that natural disasters will occur more frequently and intensely in the future than before [5].

Republic of Korea has mountainous terrain across approximately $70 \%$ of its area and more than $70 \%$ of the country's precipitation occurs during the summer period (July to September) [6]. Thus, significant amount of water from rainfall is usually discharged into streams as direct runoff and the topographical characteristics of the land aid this discharge. Republic of Korea has suffered from both frequent floods aided by the direct runoff in the summer period and droughts caused by water scarcity due to unbalanced rainfall during the crop growing seasons. These repetitive natural disasters have caused great economic losses and uncertainties in sustainable water resources management plans across the country every year [7]. 
For these reasons, the Korean government has been striving to reduce the potential risks (i.e., drought, flood, etc.) of effects from climate change and recently suggested the Four Major Rivers Restoration Project as one solution [8]. In order to verify the effects of this project at the field level, various factors, such as the dynamic interactions between meteorological and hydrological processes across the land surface, rainfall-runoff processes, seasonal weather predictions, ecosystem dynamics and alteration, and regional characteristics, need to be studied.

In Republic of Korea, Korea Meteorological Administration (KMA) provides weather predictions based on various climate change scenarios [3]. Kim et al. [9] and Lee et al. [10] assessed flood vulnerability at watershed-scales using KMA-based climate predictions. Kwon et al. [11] explored the boundary changes in a subtropical climate region (Republic of Korea) using the A1B emission scenario. Park et al. [12] evaluated the impacts of climate change on river water quality at the Chungju-dam watershed using a soil water assessment tool (SWAT) [13] model. These studies show that climate change scenarios have been used to predict and assess longterm, sustainable development and management of water resources.

The use of weather prediction has been steadily increasing, but global circulation models (GCMs)/regional scale models (RCMs) provided by the KMA still have limitations for application at local/regional scales due to the discrepancy in scale between GCMs/RCMs and field-scale (or modeling) resolutions [14]. These drawbacks may cause large uncertainties when planning for sustainable water resources management for the future. For these reasons, bias in the GCMs/RCMs needs to be corrected by comparing the weather history of local regions.

Currently, several bias-correction schemes, such as change factor (CF) [15], quantile mapping (QM) [16], and multiple linear regression [17], which have been developed and improved since a few decades ago, exist. CF is a simple downscaling method that uses the average values of observations and predictions. This method is conducted by simply scaling the average change factor to each day [18]. Due to its simplicity, this concept has been used in many climate related bias-correction applications [19-23]. The QM scheme corrects GCMs/RCMs based on the cumulative distribution function (CDF) with a statistically good match [24]. The QM method has been widely employed to correct the bias of GCMs/RCMs (e.g., [18, 25-27]). Both CF and QM have their main advantage in that the statistical approach to bias corrections has better computational efficiency than other physical-based approaches $[18,23]$. However, bias correction using the CF method changes only the average, maxima, and minima of the climatic index in scenarios, while all the other properties, such as the number of wet/dry days and the variance of temperature, remain unchanged [28, 29]. QM has limitations in capturing extreme values beyond the range of observations (e.g., $[24,30]$ ). Since CF and QM both have their advantages/disadvantages for bias correction, a linked CF and QM approach that can overcome both of their disadvantages may perform better in correcting GCM/RCM data to get them closer to historical observations.

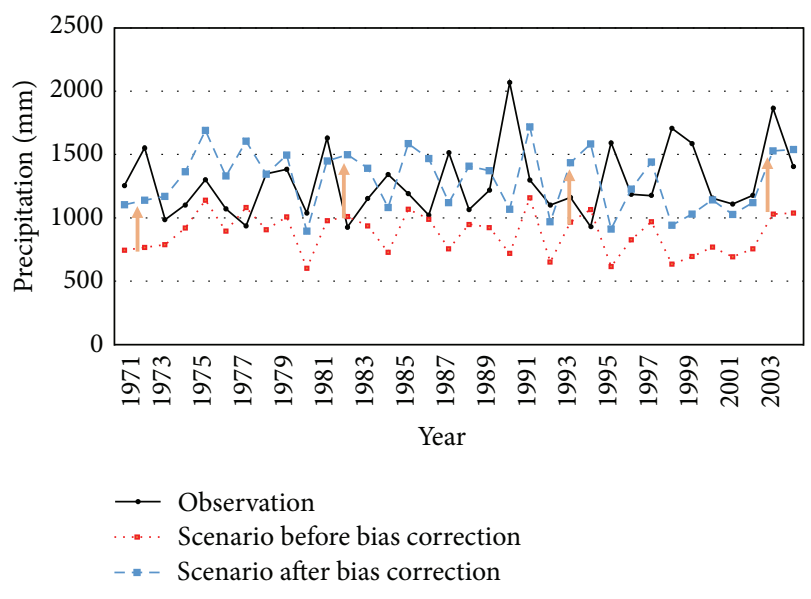

FIGURE 1: Bias correction using the change factor.

Thus, we explored an enhanced bias-correction approach for improving the applicability of GCMs and RCMs to local regions. The objectives of this study were twofold: (1) to propose an enhanced bias-correction method linking CF and QM and (2) to assess the performance of our approach at field level. Our proposed approach can be substantially more useful for providing realistic bias-corrected GCM/RCM projections that are closer to the weather history and for creation and implementation of sustainable long-term water resources management plans for the future.

\section{Experimental Section}

\subsection{Literature Review}

2.1.1. Bias-Correction Methods. The change factor (CF) method has been widely used for bias corrections because of its simplified approach. Equation (1) describes how the CF corrects the bias between observations and predictions:

$$
P_{\mathrm{RCM}, \mathrm{fut}}^{\prime}=P_{\mathrm{RCM}} \times\left(\frac{\bar{P}_{\text {meas,his }}}{\bar{P}_{\mathrm{RCM}, \mathrm{his}}}\right),
$$

where $P_{\mathrm{RCM}, \text { fut }}^{\prime}$ is the transformed future precipitation, $P_{\mathrm{RCM}}$ is the predicted future precipitation, $\bar{P}_{\text {meas,his }}$ is the average of observed precipitation, and $\bar{P}_{\mathrm{RCM} \text {,his }}$ is the average of historical A1B precipitation.

The CF approach calculates the average values of the monthly/yearly observations and predictions. Then, the CF estimates the bias-correction coefficients indicating the differences between the observations and predictions and shifts the predicted results to the observation data based on the calculated coefficients (Figure 1).

The quantile mapping (QM) method, proposed by Panofsy and Brire [16], minimizes the differences between the observed/predicted data based on empirical probability distributions. Figure 2 shows how the QM shifts the predicted data to the observations with the same nonexceedance probability. Here, we used the one-to-one mapping scheme with the order statistics of the observed simulated data, instead 


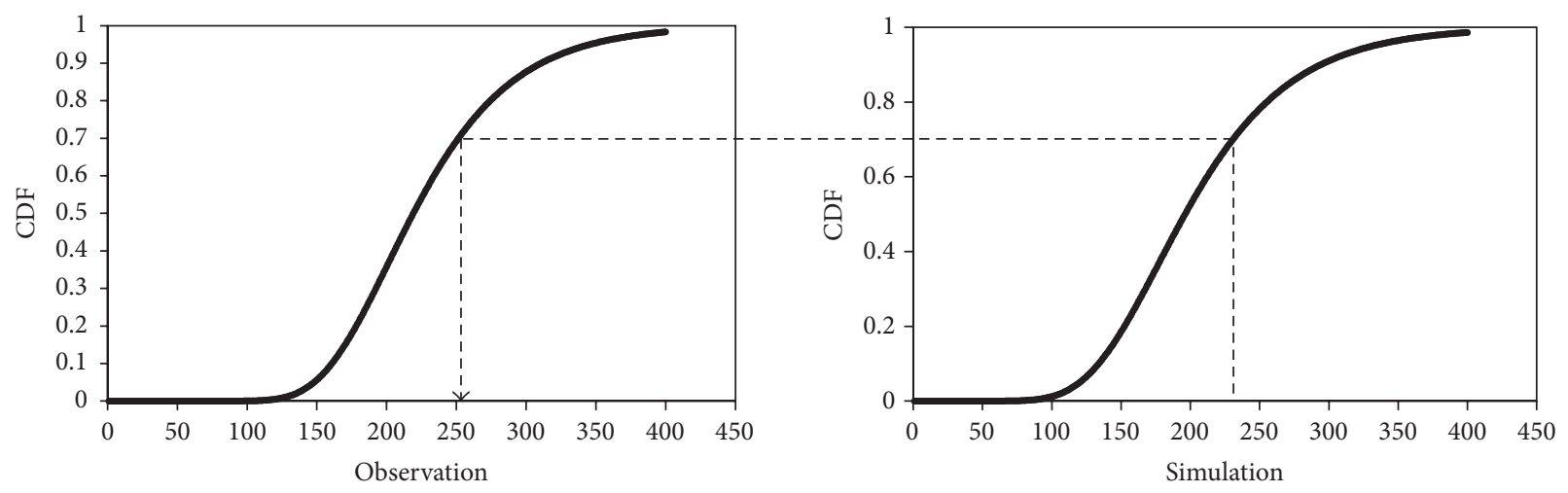

FIGURE 2: Schematics of the quantile mapping method.

of fitting the mathematical model based on the cumulative distribution functions:

$$
\begin{gathered}
P(a \leq x \leq b)=\sum_{a \leq x_{i \leq} \leq b} P\left(x_{i}\right), \\
F(x)=P(X \leq x)=\sum_{X \leq x_{i}} P\left(x_{i}\right), \\
Z_{i}=F_{o i}^{-1}\left(F_{s i}\left(\widehat{Y}_{i}\right)\right)
\end{gathered}
$$

where $F_{o i}$ is the cumulative distribution function of the observed daily data for day $i, F_{s i}$ is the cumulative distribution function of the simulated data from historical simulations, and $\widehat{Y}_{i}$ and $Z_{i}$ are the simulated and transformed (biascorrected) data, respectively, for day $i$ (2).

The transformed predictions have the same probability distribution with the observations, but QM has a limitation in generating distributions on a monthly basis due to the small amount of data points available [31-34].

2.1.2. Climate Change Scenarios. The Intergovernmental Panel on Climate Change (IPCC) provides past and future weather scenarios based on various meteorological, socioeconomic, and environmental data for assessing the impacts of climate changes [5]. Based on these scenarios from the IPCC, the KMA has generated global circulation model (GCM) and regional climate model (RCM) outputs. RCM predictions have relatively finer-scale resolutions $(27 \mathrm{~km} \times$ $27 \mathrm{~km}$ ) compared to GCMs (i.e., $3.75^{\circ} \times 3.75^{\circ}$, approximately $\sim 400 \mathrm{~km}$ ). The Special Report on Emissions Scenarios (SRES, the 3rd Assessment Report) by the IPCC provides four different storylines (A1, A2, B1, and B2) based on different demographic, social, economic, technological, and environmental developments. The A1B (balanced emphasis on all energy sources) scenario is one of the most realistic future climate scenarios provided by the KMA.

The KMA used the AlB scenario as the input data to a GCM (ECHO-G) that included the Coupled Climate model comprised of the Atmosphere model (ECHAM4), the Thawing-Ocean model (HOPE-G), and the Atmosphere
Ocean Coupled model (OASIS) for generating GCM scenarios. In addition, high-resolution climate change scenarios in Republic of Korea were provided by the KMA using the MM5 (5th Generation Mesoscale Model) [35] based regional climate model (Figure 3). The KMA climate scenarios using GCM (ECHO-G)/RCM (MM5) reflect the Korean climate features well [36]. For this reason, KMA recommends the use and integration of their scenarios as national standard science information in policies, projects, and studies related to climate change in Republic of Korea. In this regard, numerous studies have used KMA scenarios for climate change applications in Republic of Korea [37-44]. Thus, we selected the KMA climate change scenarios using the A1B scenario for assessing our proposed approach.

\subsection{Materials and Method}

2.2.1. Enhanced Bias-Correction Approach Linking the CF and QM Methods. Both the CF and QM methods have their advantages and disadvantages in the bias-correction process. Bias-corrected (transformed) precipitation of the future will vary based on the selection of either CF or QM. In general, rainfall quantities/frequencies considerably influence the occurrence of floods/droughts. As mentioned in Section 1, heavy rainfall events/amounts, such as the $941.5 \mathrm{~mm}$ rainfall from July to September in 2004 [23], have been generated during the summer period indicating that small uncertainties (especially for rainfall amounts) in bias-correction methods and inherently ill-posed GCM data may lead to disastrous damages across the country. Thus, these uncertainties need to be reduced for efficient water resources management by policy/decision makers. Although the linked CF and QM method can contribute to a reduction in uncertainties in the bias-correction methods (CF or QM), the inherent uncertainty caused by drawbacks within the GCM/RCM data provided by the IPCC/KMA is unavoidable. To date, correcting daily GCM/RCM data is still a challenge globally. Therefore, we corrected the bias of monthly (precipitation) predictions using CF and then, using the QM scheme, shifted the CF-based bias-corrected predictions to the historical observations as shown in Figure 4. 


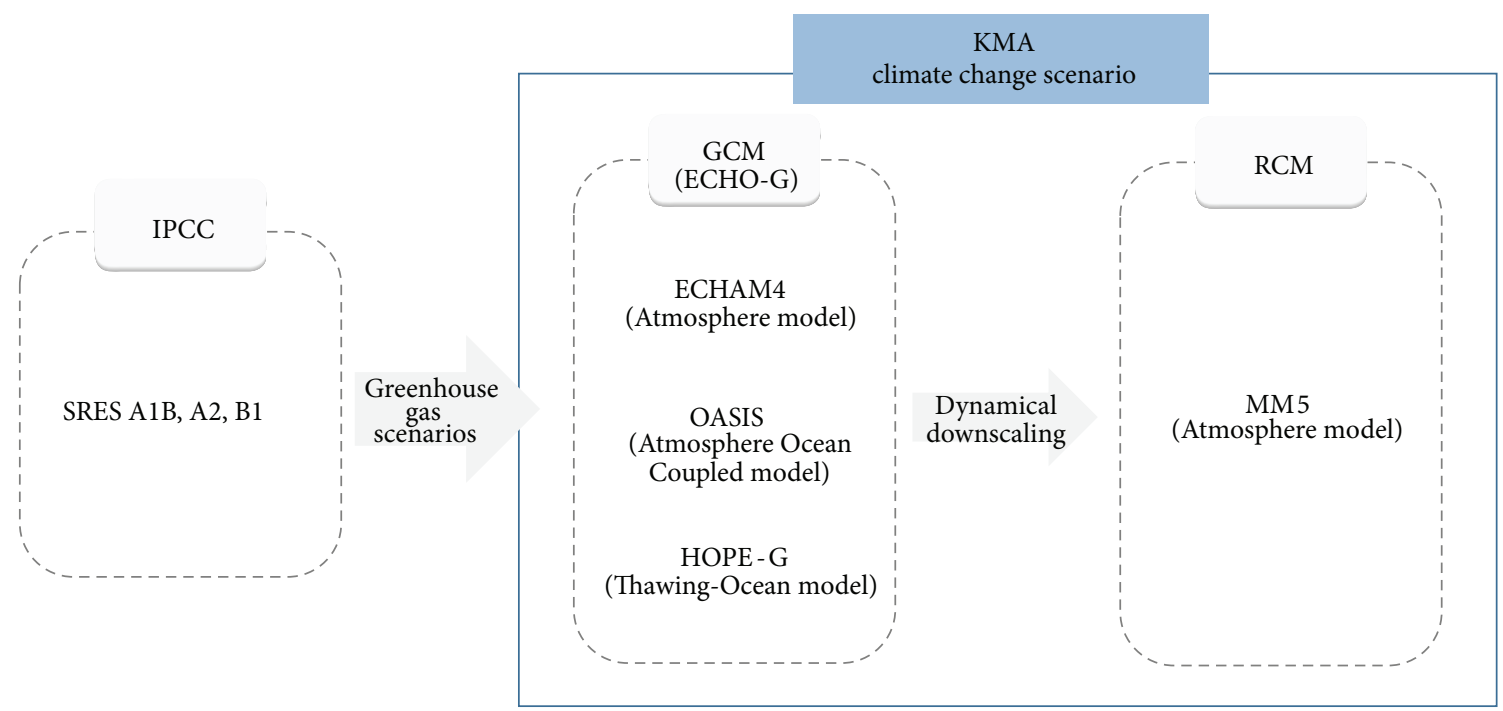

FIGURE 3: Generation of the climate predictions using the SRES A1B scenarios retrieved from KMA.

2.2.2. Application of the CF, QM, and $C F+Q M$ Bias Correction. In this study, the Songwol-dong site in Seoul, Republic of Korea, shown in Figure 5, was selected to assess the bias correction of the $\mathrm{A} 1 \mathrm{~B}$ precipitation scenario using three methods (CF, QM, and CF + QM) against the observed precipitation data during a baseline period. The bias-correction coefficients (change factors for the CF method and a CDF for the QM method) obtained from the bias correction during the baseline period were applied to the A1B precipitation scenario. Twelve change factors, one for each month, were estimated, and a CDF was estimated based on the relationship between the observed precipitation data and the A1B precipitation scenario during a baseline period.

For evaluation of the bias correction by the three methods, we divided the observation period (1983-2012) into two groups: the baseline period (1983-1997) and the validation period (1998-2012). We obtained the bias-correction coefficients of CF and QM between the A1B precipitation scenario (1983-1997) and the observed precipitation data through bias correction during a baseline period (1983-1997). Then, the bias-correction coefficients were applied to the A1B precipitation scenario (1998-2012) for comparison with the observed precipitation (1998-2012) for validation.

The weather in Republic of Korea shows seasonal changes due to the monsoon climate. For this reason, we classified the monthly averaged precipitation into four categories (January-March, April-June, July-September, and OctoberDecember) and assessed the bias-corrected data using the coefficient of determination $\left(R^{2}\right)$, Nash-Sutcliffe efficiency (NSE), and root mean square error (RMSE). Then, we estimated the bias-correction coefficients of the A1B precipitation scenario relative to the observed precipitation data using another baseline period (1983 to 2012) for bias correction of future climate change scenario. We corrected the A1B precipitation projections for the future (2016-2100) based on the derived bias-correction coefficients from 1983 to 2012, and their characteristics/statistics were analyzed.
The $R^{2}$ measures the degree of collinearity between observations and simulations:

$$
R^{2}=\frac{\left(\sum_{i=1}^{n}\left(y_{\mathrm{obs}, i}-\bar{Y}_{\mathrm{obs}}\right)\left(y_{\mathrm{sim}, i}-\bar{Y}_{\mathrm{sim}}\right)\right)^{2}}{\sum_{i=1}^{n}\left(y_{\mathrm{obs}, i}-\bar{Y}_{\mathrm{obs}}\right)^{2} \sum_{i=1}^{n}\left(y_{\mathrm{sim}, i}-\bar{Y}_{\mathrm{sim}}\right)^{2}},
$$

where $y_{\mathrm{obs}, i}$ is the $i$ th observation, $y_{\mathrm{sim}, i}$ is the $i$ th simulation, $\bar{Y}_{\text {obs }}$ is the mean of the observations, $\bar{Y}_{\text {sim }}$ is the mean of the simulations, and $n$ is the total number of observations.

The NSE is a normalized statistic that gives the relative magnitude of the residual variance compared to the observed variance [45], as shown in

$$
\mathrm{NSE}=1-\left(\frac{\sum_{i=1}^{n}\left(y_{\mathrm{obs}, i}-y_{\mathrm{sim}, i}\right)^{2}}{\sum_{i=1}^{n}\left(y_{\mathrm{obs}, i}-\bar{Y}_{\mathrm{obs}}\right)^{2}}\right),
$$

where an NSE value of 1 indicates perfect agreement between observations and simulations.

The RMSE is one of the commonly used error index statistics for observed and simulated data [46], as shown in

$$
\mathrm{RMSE}=\sqrt{\frac{\sum_{i=1}^{n}\left(y_{\mathrm{obs}, i}-y_{\mathrm{sim}, i}\right)^{2}}{n}},
$$

where an RMSE of zero indicates perfect agreement between observations and simulations.

\section{Results and Discussion}

3.1. Evaluation of Bias Correction Using the Three Methods. In Republic of Korea, 60-70\% of the yearly precipitation amount [47] is usually generated during the summer period (July to September). To be prepared for natural disasters (drought, flood, etc.) and ensuring sustainability of water resources, efficient water management plans need to be formulated 


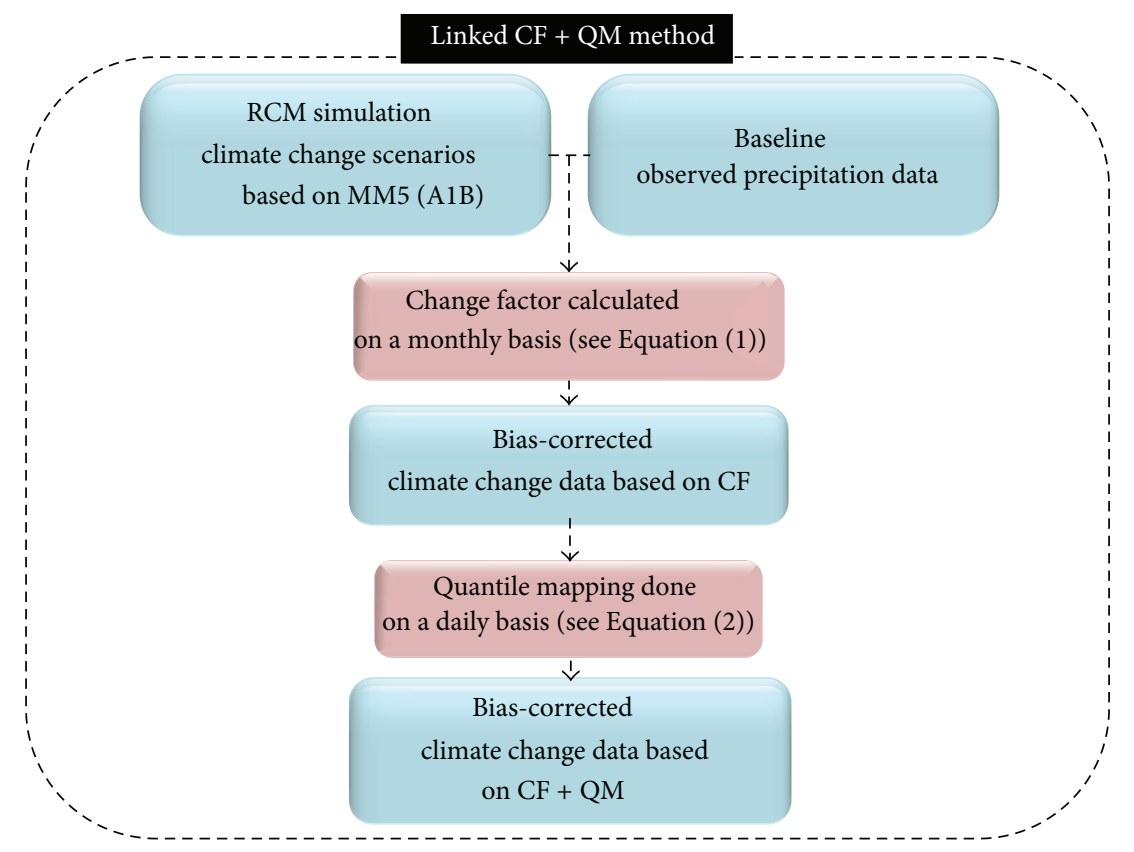

FIGURE 4: Procedure of the linked CF + QM method for bias corrections.

TABLE 1: Statistical analysis of the observed and bias-corrected daily precipitation for bias correction and validation.

\begin{tabular}{|c|c|c|c|c|c|c|}
\hline & \multicolumn{3}{|c|}{ Baseline period (1983-1997) } & \multicolumn{3}{|c|}{ Validation period (1998-2012) } \\
\hline & CF & QM & $\mathrm{CF}+\mathrm{QM}$ & $\mathrm{CF}$ & QM & $\mathrm{CF}+\mathrm{QM}$ \\
\hline \multicolumn{7}{|l|}{ Jan.-Mar. } \\
\hline$R^{2}$ & 0.899 & 0.939 & 0.914 & 0.972 & 0.984 & 0.986 \\
\hline NSE & 0.855 & 0.877 & 0.904 & 0.939 & 0.510 & 0.879 \\
\hline RMSE (mm) & 1.659 & 1.527 & 1.352 & 0.928 & 2.630 & 1.306 \\
\hline \multicolumn{7}{|l|}{ Apr.-Jun. } \\
\hline$R^{2}$ & 0.977 & 0.991 & 0.994 & 0.990 & 0.969 & 0.983 \\
\hline NSE & 0.971 & 0.502 & 0.993 & 0.839 & 0.931 & 0.887 \\
\hline RMSE (mm) & 1.817 & 7.546 & 0.899 & 4.676 & 3.067 & 3.919 \\
\hline \multicolumn{7}{|l|}{ Jul.-Sep. } \\
\hline$R^{2}$ & 0.958 & 0.916 & 0.998 & 0.859 & 0.852 & 0.922 \\
\hline NSE & 0.887 & 0.860 & 0.998 & 0.703 & 0.700 & 0.916 \\
\hline RMSE (mm) & 8.166 & 9.113 & 1.176 & 17.501 & 17.579 & 9.287 \\
\hline \multicolumn{7}{|l|}{ Oct.-Dec. } \\
\hline$R^{2}$ & 0.975 & 0.978 & 0.969 & 0.981 & 0.990 & 0.990 \\
\hline NSE & 0.968 & 0.508 & 0.966 & 0.709 & -1.708 & 0.496 \\
\hline RMSE (mm) & 1.072 & 4.180 & 1.097 & 2.055 & 6.273 & 2.708 \\
\hline
\end{tabular}

for the heavy rainfall period. The selection of precise biascorrection methods can help in obtaining reliable projected precipitation changes across the Korean peninsula for the summer period in the future, which can help in mitigating potential risks from natural disasters.

Table 1 presents the statistical analysis of the biascorrected precipitation using the three methods. The biascorrected precipitation results of the combined CF + QM method were considerably improved for baseline period (1983-1997) and validation period (1998-2012) as compared to those of the CF-only or QM-only methods; however, there were no significant differences between the results of the CF, $\mathrm{QM}$, and CF + QM methods for the dry seasons (January to March, April to June, and October to December). The CF method overestimated the bias-corrected A1B precipitation scenarios as compared to the baseline precipitation data while the bias-corrected precipitation by the QM scheme was underestimated for baseline and validation periods. The fact that the CF + QM method performed better at correcting the $\mathrm{A} 1 \mathrm{~B}$ precipitation scenarios relative to the baseline precipitation data for the bias correction and validation of the summer period (July to September) supports the robustness 


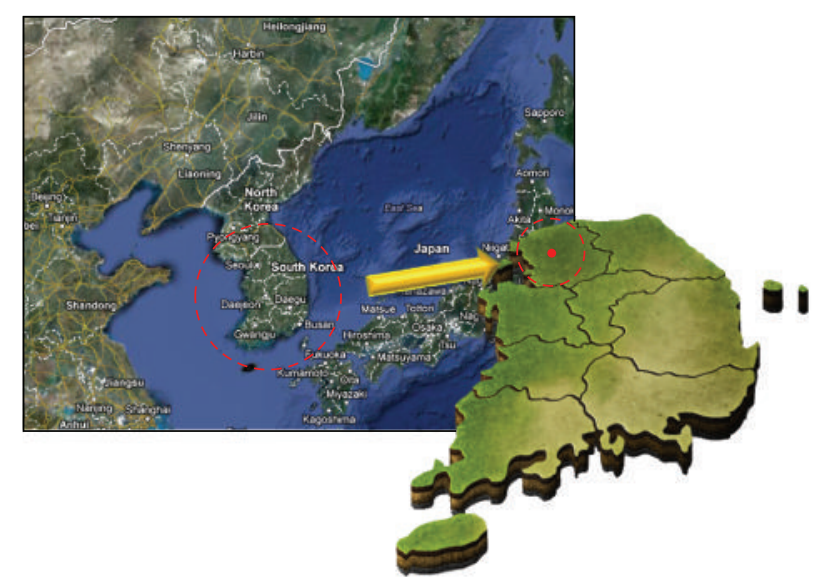

FIgURE 5: Location of the Songwol-dong site in Republic of Korea.

of our proposed bias-correction method (combined CF + QM) for application to heavy rainfall seasons. Even though uncertainties exist in the bias correction/validation periods, the bias-corrected results of the CF + QM method are closer to the observations than those of the CF-only or QM-only methods, as shown in Figures 6 and 7.

3.2. Bias Corrections of the A1B Precipitation Projections for the Future. Since the CF + QM method showed good results in validation, we corrected the A1B precipitation scenario from 1983 to 2100 at the identical region. Note that we conducted bias correction using the three methods for the comparison using the baseline precipitation forcings (1983 to 2012), and then the bias-correction coefficients were applied to the precipitation projections from 2016 to 2100 .

Figure 8 shows the comparison of the observations and transformed (bias-corrected) predictions based on the three methods. Comparison of the results of the CF, QM, and $\mathrm{CF}+\mathrm{QM}$ methods shows that the monthly distribution of the transformed daily precipitation (5th/25th/50th/75th/95th percentiles and mean) from the QM is considerably different from the observations. These results imply that the QM is limited in correcting monsoon climatic predictions because intensive rainfall frequencies/amounts during heavy rainfall periods might cause over-/underestimations in correcting bias.

The results of the $\mathrm{CF}$ and $\mathrm{CF}+\mathrm{QM}$ methods have similar distributions as shown in Figure 8. The CF method performed better in correcting the bias of the monthly precipitation data, but the CF had a limitation in that it was highly dependent on the distribution of the predicted precipitation data.

Table 2 shows the comparison of the monthly maximum precipitation data from the observations and transformed data using the $\mathrm{CF}$ and $\mathrm{CF}+\mathrm{QM}$ methods. With respect to the monthly observation of $1,131.0 \mathrm{~mm}$ (the monthly maximum precipitation) in July, the CF method generated an amount of $1,540.3 \mathrm{~mm}$ (36.2\% difference), while the CF + QM method generated $1,319.4 \mathrm{~mm}$, a $16.7 \%$ lower deviation than the $\mathrm{CF}$.
TABLE 2: Comparison of the maximum monthly precipitation from 1983 to 2012.

\begin{tabular}{lccccc}
\hline Month & $\begin{array}{c}\text { Obs. } \\
(\mathrm{mm})\end{array}$ & $\begin{array}{c}\text { CF } \\
(\mathrm{mm})\end{array}$ & $\begin{array}{c}\text { Diff. } \\
(\%)\end{array}$ & $\begin{array}{c}\text { CF + QM } \\
(\mathrm{mm})\end{array}$ & $\begin{array}{c}\text { Diff. } \\
(\%)\end{array}$ \\
\hline Jan. & 62.2 & 50.3 & -19.1 & 54.9 & -11.7 \\
Feb. & 69.5 & 67.5 & -2.9 & 79.4 & 14.2 \\
Mar. & 123.5 & 100.2 & -18.9 & 113.3 & -8.3 \\
Apr. & 157.0 & 145.6 & -7.3 & 166.2 & 5.9 \\
May & 291.3 & 222.4 & -23.7 & 247.5 & -15.0 \\
Jun. & 497.2 & 461.1 & -7.3 & 474.26 & -4.6 \\
Jul. & 1131.0 & 1540.3 & 36.2 & 1319.4 & 16.7 \\
Aug. & 1237.8 & 1535.6 & 24.1 & 1271.0 & 2.7 \\
Sep. & 671.5 & 506.2 & -24.6 & 463.6 & -31.0 \\
Oct. & 214.5 & 204.4 & -4.7 & 235.9 & 10.0 \\
Nov. & 154.5 & 104.0 & -32.7 & 118.7 & -23.2 \\
Dec. & 71.4 & 67.3 & -5.7 & 74.3 & 4.1 \\
\hline
\end{tabular}

However, the monthly averages of the observed and transformed precipitation data in July were identical at $425 \mathrm{~mm}$ (Figure 8). In August, the maximum precipitation using the CF method was $1,535.6 \mathrm{~mm}$ (24.1\% difference as compared with the observed maximum precipitation of 1,237.8 mm). On the contrary, the CF + QM method generated a monthly maximum precipitation of $1,271.0 \mathrm{~mm}$, a difference of only $2.7 \%$ as compared with the observation data (Table 2).

Table 3 shows the number of days with the statistics (maximum and minimum, sum, average, and standard deviation) of the weather history and the bias-corrected/uncorrected predictions. The daily maximum transformed precipitation based on the CF method is $823.1 \mathrm{~mm}$ (July 2004), while the maximum daily precipitation of the observation data is $332.8 \mathrm{~mm}$. The total precipitation in 2004 was $1020 \mathrm{~mm}$, which is approximately $20 \%$ less than the annual average precipitation in Republic of Korea. The use of a correction factor for long periods and in dry years might overestimate the daily precipitation in bias correction. These results demonstrate that the CF method can yield inaccuracies when used for dry years because correction factors may have their limitations in reflecting the variations in yearly precipitation data. The CF method corrected well the monthly/yearly precipitation amounts as well as the number of predicted precipitation occurrences when compared to the baseline precipitation data. However, this method showed high uncertainties in matching the daily outputs as shown in the statistics (maximum, average, and standard deviation, see Table 2). However, the proposed CF + QM method provided better bias-corrected predictions than the others because it reduced the limitations of both the CF and QM methods.

The bias-uncorrected predictions generated a total precipitation amount of $68,528 \mathrm{~mm}$ for the future period (20162100), but the bias-corrected results of the CF, QM, and $\mathrm{CF}+\mathrm{QM}$ methods were $141,613 \mathrm{~mm}, 146,637 \mathrm{~mm}$, and $140,665 \mathrm{~mm}$, respectively. Although the total quantities of the 


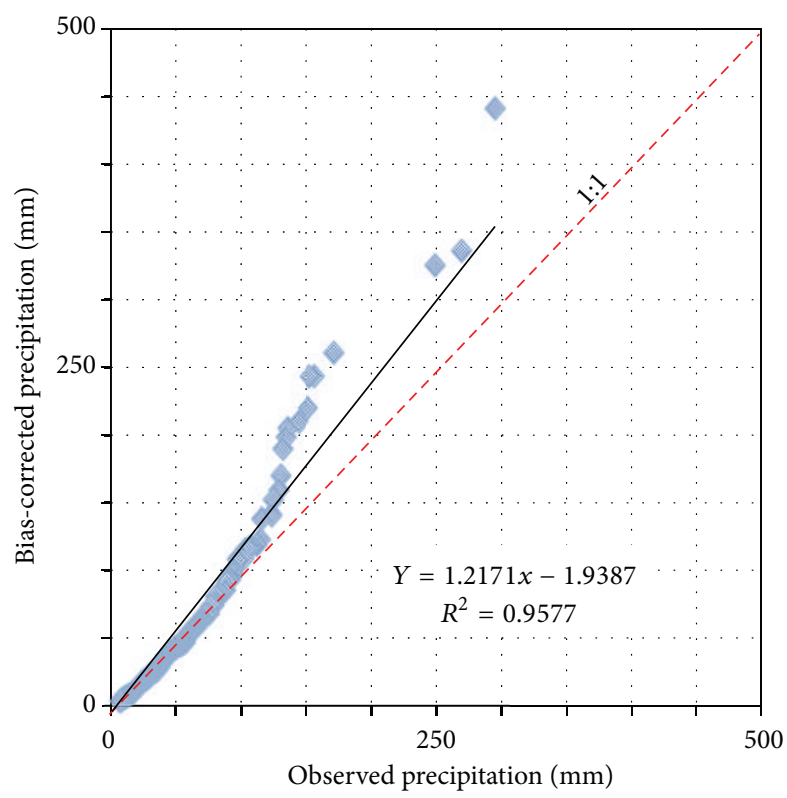

(a) $\mathrm{CF}$

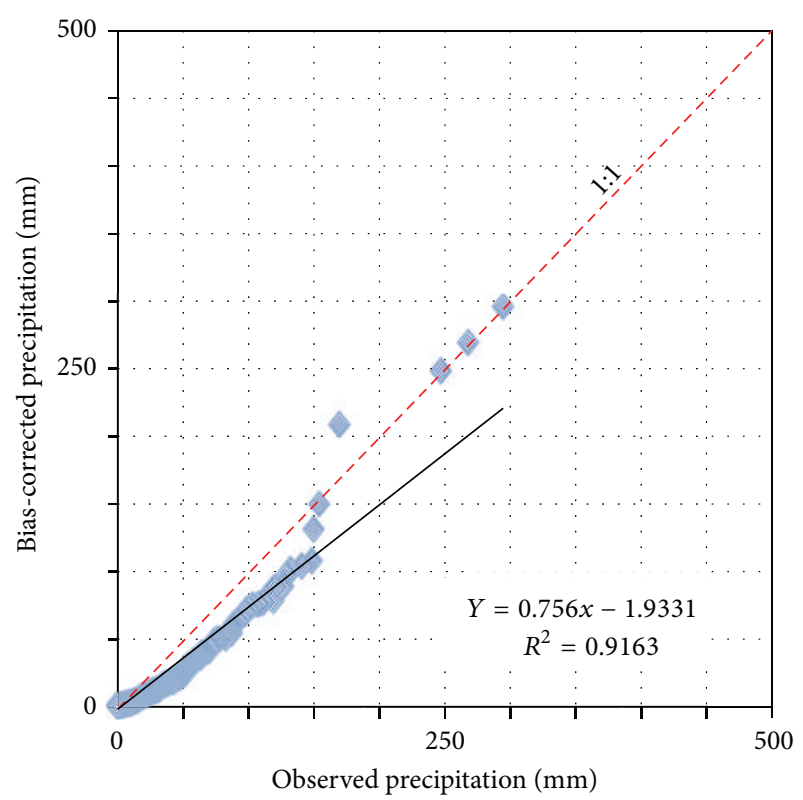

(b) QM

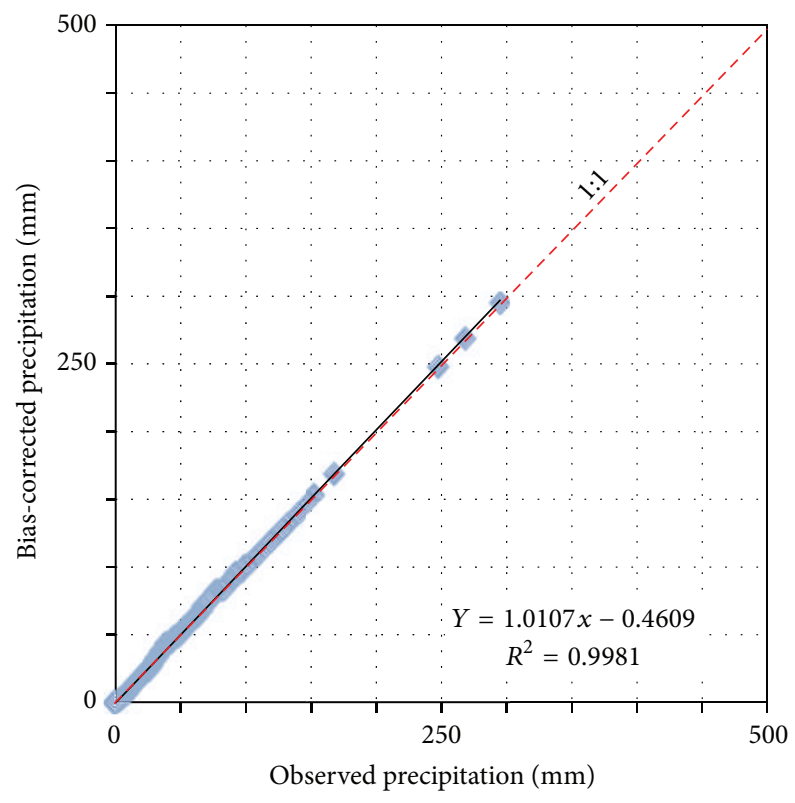

(c) $\mathrm{CF}+\mathrm{QM}$

FIGURE 6: Scatter plots of the observed and bias-corrected precipitation during the heavy rain season (July-September) from 1983 to 1997.

bias-corrected precipitation during the entire period are similar, the temporal distributions of the transformed future precipitation data showed large differences as shown in Figures 9,10 , and 11 . The yearly precipitations have extremely high frequencies from 2050 to 2070 for CF and 2070 to 2090 for QM. However, the degree of high frequencies corrected by the $\mathrm{CF}+\mathrm{QM}$ method was relatively lower than those by the CFonly and QM-only methods, as shown in the bias-corrected results of bias correction and validation. This demonstrates that the CF + QM method can improve the limitations of the individual CF and QM methods. Figure 12 shows the ranges of the yearly precipitation predictions transformed by $\mathrm{CF}$,
$\mathrm{QM}$, and $\mathrm{CF}+\mathrm{QM}$ with five-year intervals. Figure 12 shows that the bias-corrected predictions based on the CF + QM are usually located near the center, between those of the CF and QM. Thus, using a single bias-correction method (CF or $\mathrm{QM}$ ) has relatively higher uncertainties in providing accurate future precipitation projections as compared to the combined $\mathrm{CF}+\mathrm{QM}$ method. Furthermore, errors incorporated within bias-correction methods might be propagated into future projections that may be used by decision makers. Therefore, appropriate bias-correction methods that reduce errors in future precipitation projections should be used. Our results show that the CF + QM method, which can improve the 


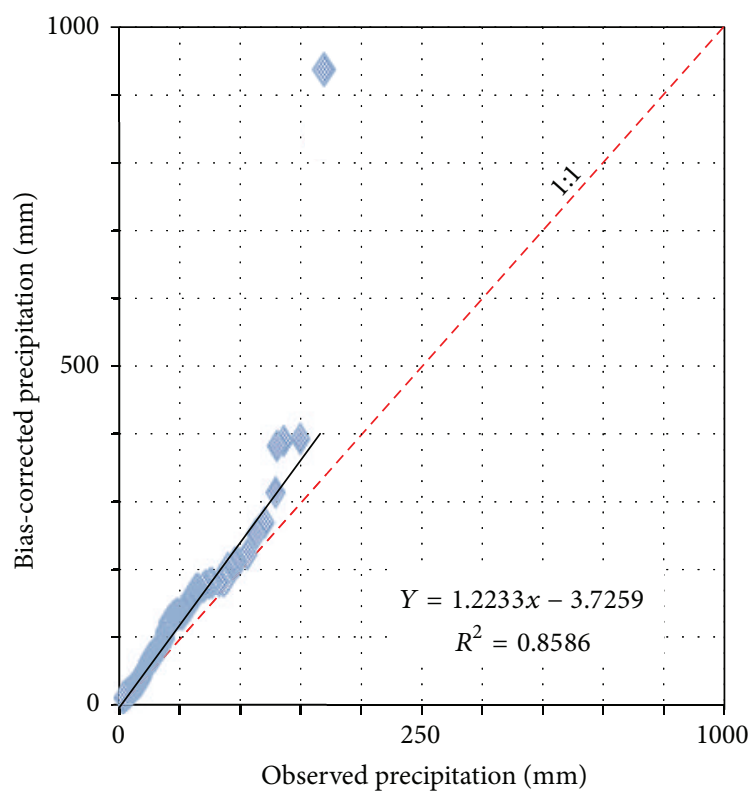

(a) $\mathrm{CF}$

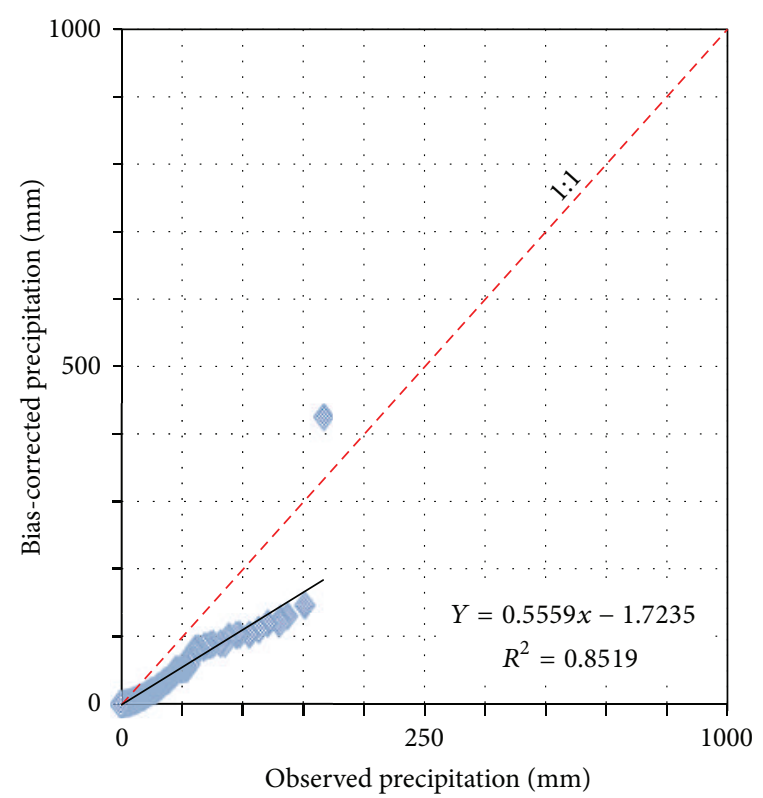

(b) QM

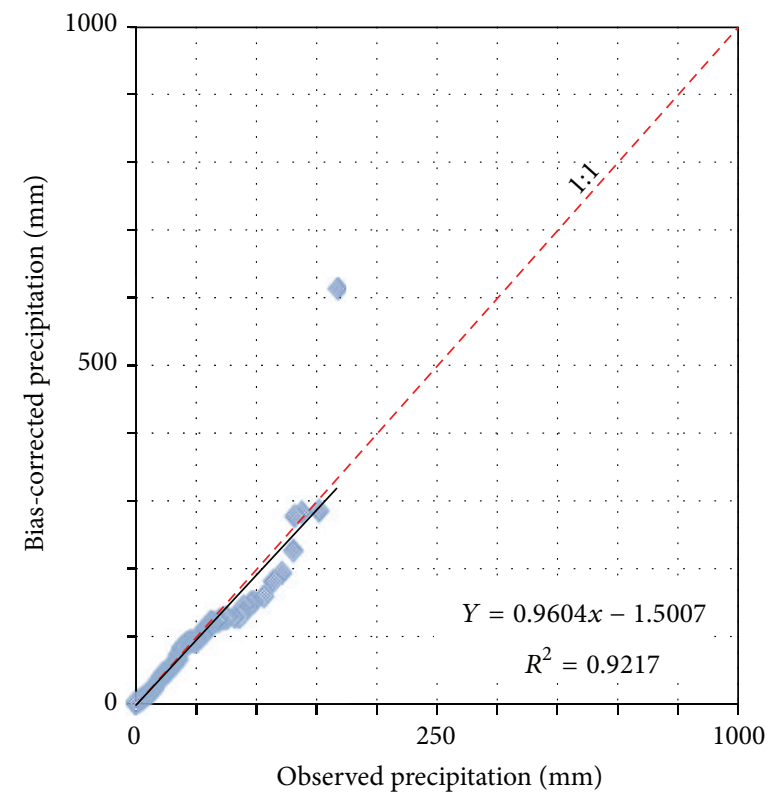

(c) $\mathrm{CF}+\mathrm{QM}$

FIGURE 7: Scatter plots of the observed and validated precipitation during the heavy rain season (July-September) from 1998 to 2012.

limitations of the CF and QM methods, can be appropriate for generating transformed precipitation data using various climate change scenarios.

\section{Conclusions}

Preparations for and adaptations to climate change are planned or ongoing throughout the world. This study suggests a combined bias-correction $(\mathrm{CF}+\mathrm{QM})$ method that combines the existing $\mathrm{CF}$ and QM methods to help prepare for the negative effects of climate change.
To assess the performance of the proposed method for bias correction for long time periods, bias corrections were conducted for the study period (1983-2012) for the Songwoldong site in Republic of Korea. The first 15 years (1983-1997) were used as a baseline period for estimating bias-correction coefficients, and we validated three methods for the latter 15 years (1998-2012). We classified the study period into four categories (January-March, April-June, July-September, and October-December) for assessing the characteristics of seasonality when correcting projected precipitation bias. Then, we tested/compared the performance of the CF-only, $\mathrm{QM}$-only, and CF + QM methods for the bias correction 


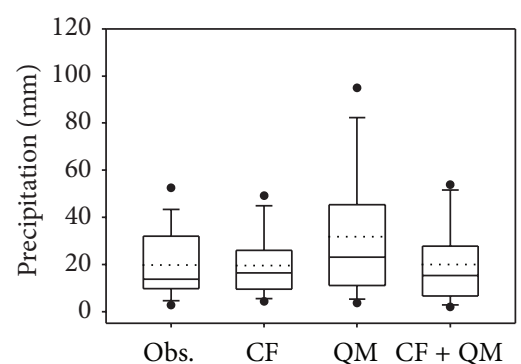

(a) January

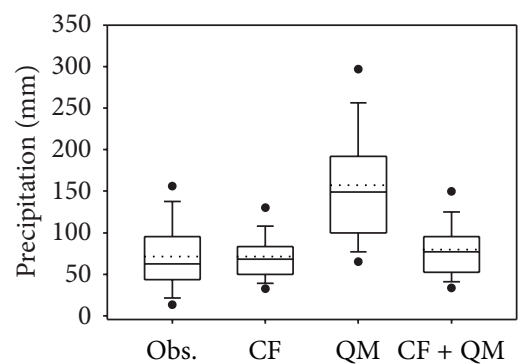

(d) April

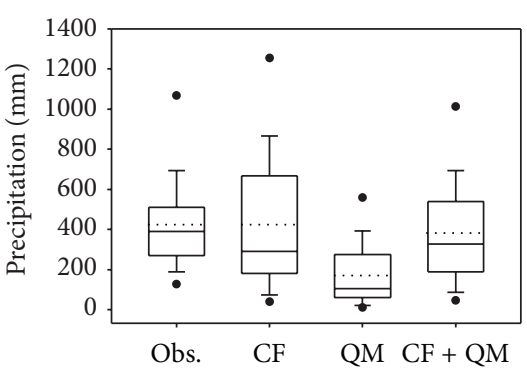

(g) July
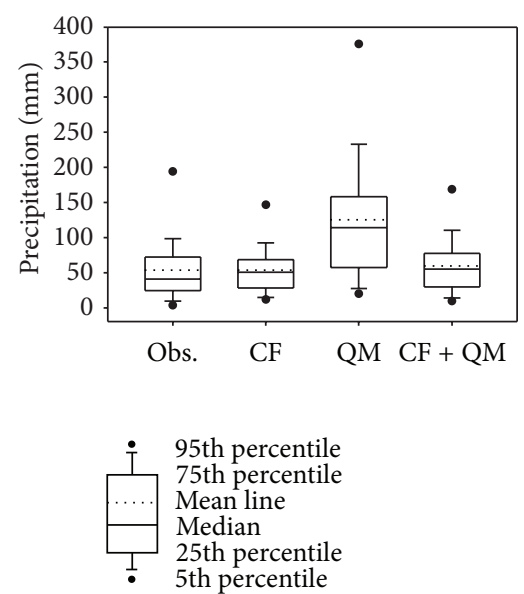

(j) October

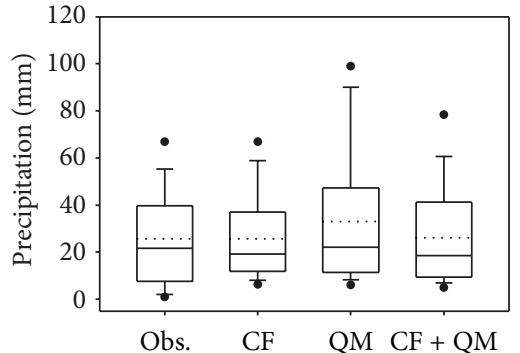

(b) February

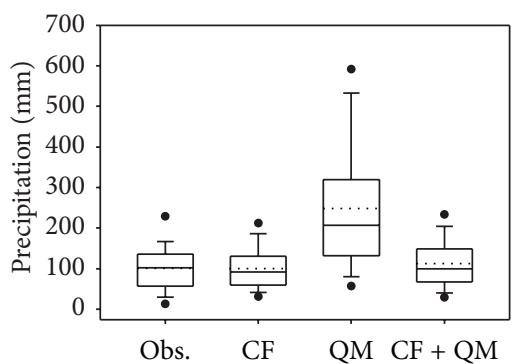

(e) May

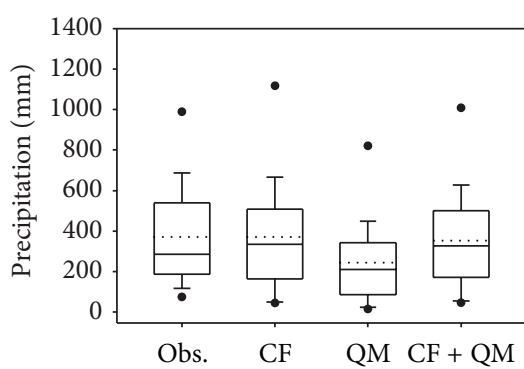

(h) August
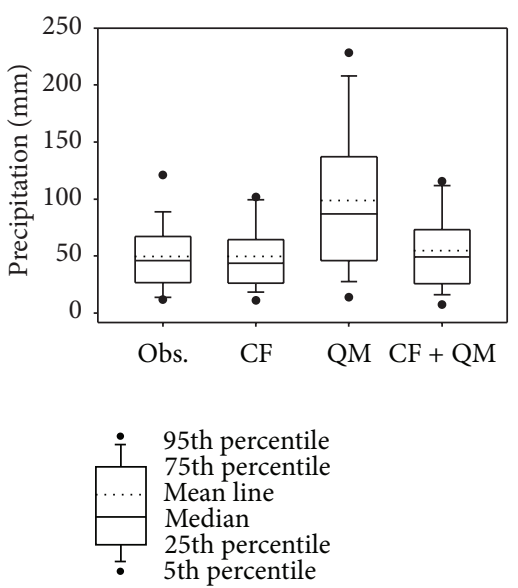

(k) November

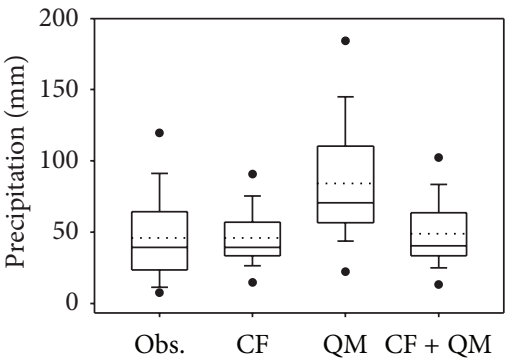

(c) March

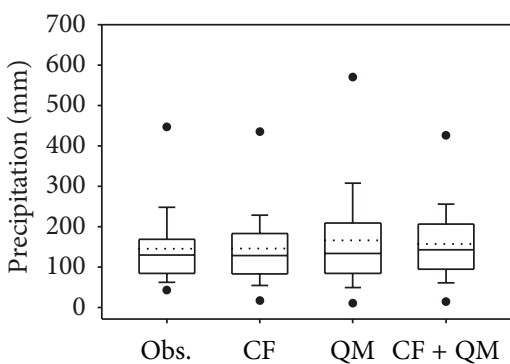

(f) June

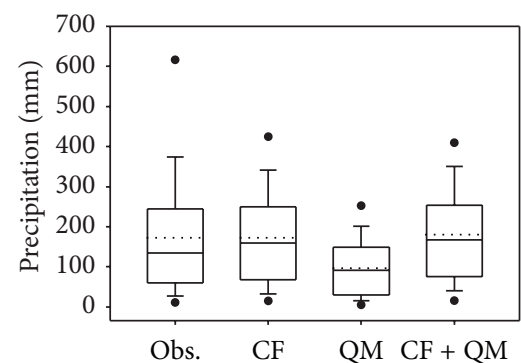

(i) September
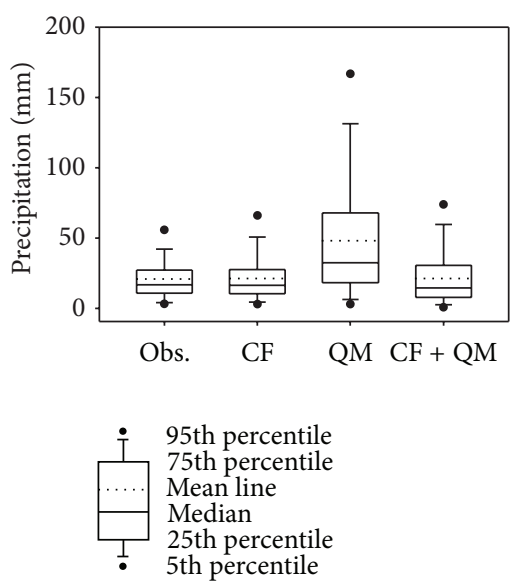

(l) December

FIGURE 8: Distribution of the monthly precipitation from 1983 to 2012.

and validation periods. Although the $\mathrm{CF}+\mathrm{QM}$ method corrected the projected precipitation bias to the baseline precipitation data slightly better than the others, there exist no/little significant differences for the dry periods (JanuaryMarch, April-June, and October-December). However, the CF + QM method $\left(R^{2}: 0.990 / 0.990\right.$ and NSE: 0.920/0.916 for bias correction/validation) considerably improved the bias-corrected precipitation during the heavy rainfall season (July-September) compared to the CF-only $\left(R^{2}: 0.958 / 0.859\right.$ and NSE: $0.887 / 0.703$ for bias correction/validation) 
TABLE 3: Statistical analysis of the observed and bias-corrected/uncorrected daily precipitation (1983-2012).

\begin{tabular}{lcccccc}
\hline & $N^{*}$ & Min. $^{* *}$ & Max. $^{* * *}$ & Sum $^{* * * *}$ & \multicolumn{2}{c}{ Avg. $^{* * * * *}$} \\
\hline Observation & 3,293 & $<1$ & 332.8 & $45,034.5$ & 13.7 & 27.2 \\
Before bias-correction scenario & 4,218 & $<1$ & 152.4 & $21,510.9$ & 5.1 & 9.6 \\
CF & 4,218 & $<1$ & 823.1 & $45,033.5$ & 10.7 & 30.7 \\
QM & 3,377 & $<1$ & 332.8 & $45,193.1$ & 13.4 & 26.9 \\
CF + QM & 3,279 & $<1$ & 332.8 & $44,890.1$ & 13.7 & 27.2 \\
\hline
\end{tabular}

${ }^{*}$ The number of days with precipitation.

${ }^{* *}$ Minimum daily precipitation in $\mathrm{mm}$.

${ }^{* * *}$ Maximum daily precipitation in $\mathrm{mm}$.

**** Sum of daily precipitation for the entire period in $\mathrm{mm}$.

***** Average of daily average precipitation in $\mathrm{mm}$.

****** Standard deviation of daily average precipitation in $\mathrm{mm}$.

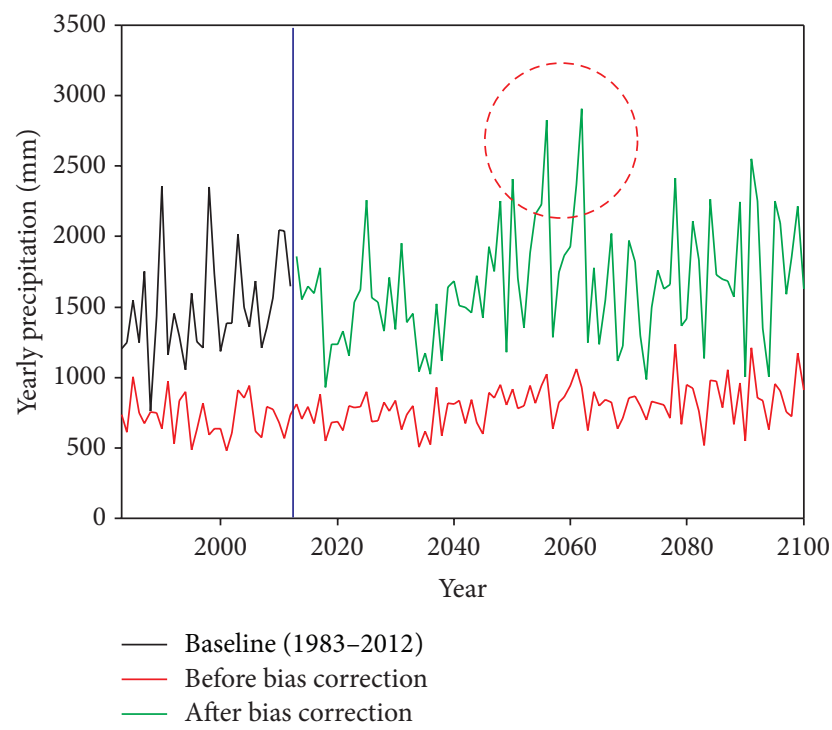

FIGURE 9: Bias-corrected yearly precipitation data using the change factor method.

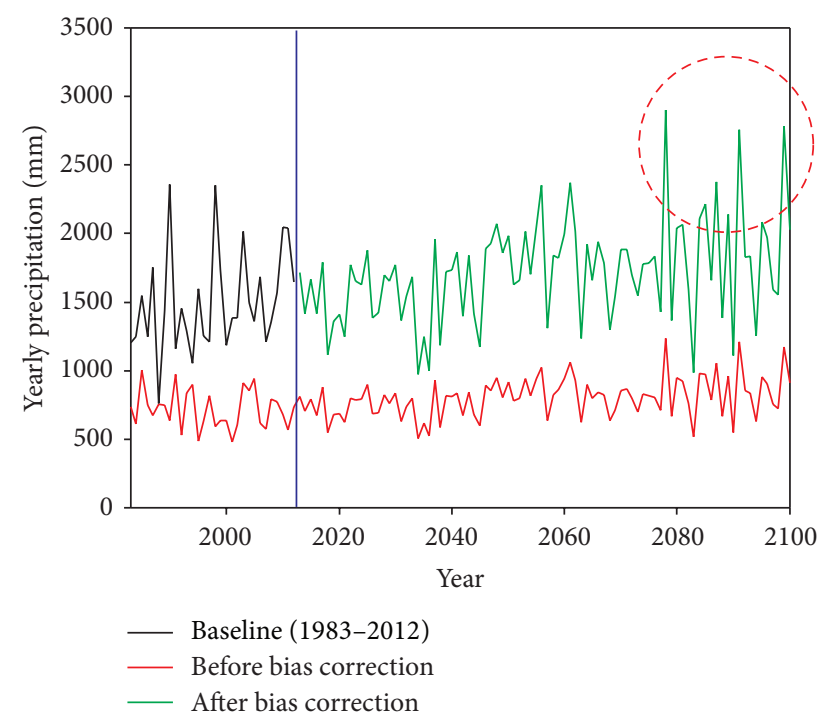

FIGURE 10: Bias-corrected yearly precipitation data using the quantile mapping method.

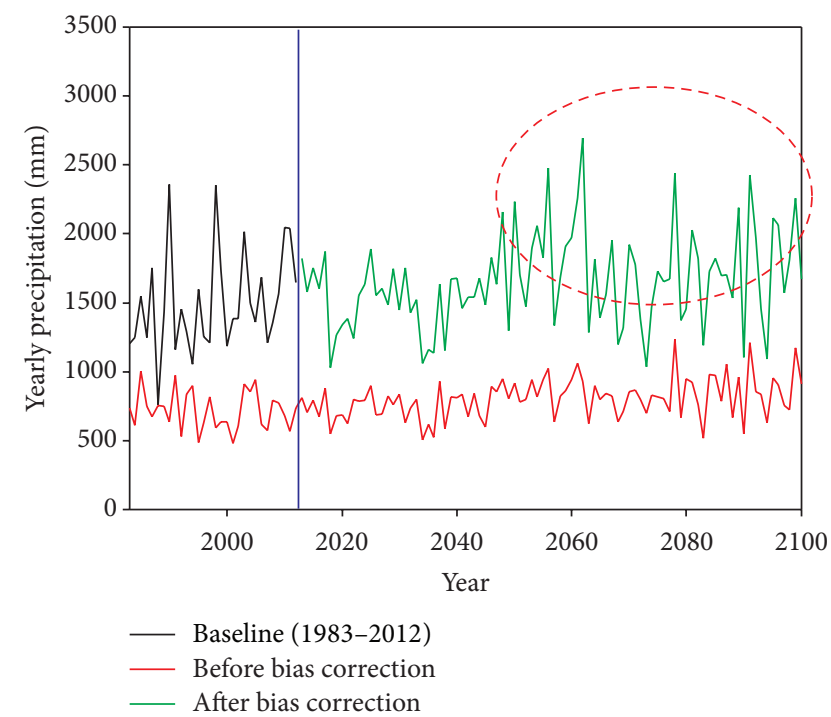

FIGURE 11: Bias-corrected yearly precipitation data using the $\mathrm{CF}+$ QM method.

and QM-only $\left(R^{2}: 0.916 / 0.852\right.$ and NSE: $0.860 / 0.700$ for bias correction/validation) methods.

After comparing the three methods for bias correction, we derived the bias-correction coefficients using the CFonly, QM-only, and CF + QM methods for the entire period (1983-2012). Then, we corrected the A1B precipitation scenario based on the estimated coefficients for the future period (2016-2100). The CF + QM method gives better biascorrected predictions with respect to statistics. In particular, the suggested CF + QM method is appropriate for monsoon climatic conditions when torrential precipitation occurs during the wet season. Furthermore, our proposed approach can contribute to a reduction in weather prediction uncertainties and the establishment of sustainable water resources management plans for mitigating natural disasters caused by future climate changes. We plan to extend the applicability and accessibility of the suggested method to the web, which will contribute considerably to the preparation for and adaptation to uncertain climate changes. 


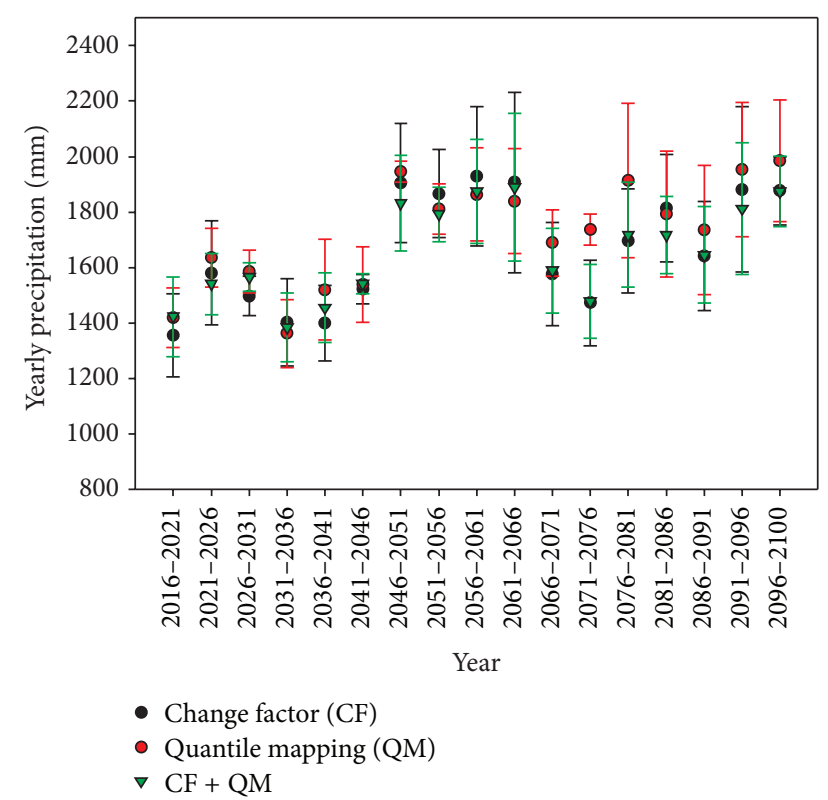

FIGURE 12: Comparison of the yearly precipitation for each 5-year interval using the $\mathrm{CF}, \mathrm{QM}$, and $\mathrm{CF}+\mathrm{QM}$ bias-correction methods.

\section{Conflict of Interests}

The authors declare that there is no conflict of interests regarding the publication of this paper.

\section{Acknowledgment}

This research was supported by the Geo-Advanced Innovative Action (GAIA) Project (no. RE201402074, Surface Soil Resources Inventory \& Integration: SSORII Research Group) in Republic of Korea.

\section{References}

[1] K. Aleklett, "Reserve driven forecasts for oil, gas \& coal and limits in carbon dioxide emissions: Peak Oil, Peak Gas, Peak Coal and Peak $\mathrm{CO}_{2}$," Joint Transport Research Centre discussion paper no. 2007-18, 2007.

[2] EPA, Climate Change Science Facts, Office of Air and Radiation, 2010.

[3] Korea Meteorological Administration (KMA), 2014, http:// www.kma.go.kr.

[4] IPCC, Climate Change 2001: Impacts, Adaptation, and Vulnerability Contribution of Working Group II to the Third Assessment Report of the Intergovernmental Panel on Climate Change, Cambridge University Press, Cambridge, UK, 2001.

[5] IPCC, Climate Change 2007: Impacts, Adaptation, and Vulnerability Contribution of Working Group II to the Fourth Assessment Report of the Intergovernmental Panel on Climate Change, Cambridge University Press, Cambridge, UK, 2007.

[6] M. H. Shin, Y. C. Shin, S. G. Heo, K. J. Lim, and J. D. Choi, "Characteristics of nonpoint source pollutant loads from forest watershed with various water quality sampling frequencies," Journal of the Korean Society of Agricultural Engineers, vol. 50, no. 2, pp. 65-71, 2008.
[7] T. J. Kwon, "Reframing sustainability in consideration of climate change and natural hazards: focusing on the U.S. natural hazards mitigation trend and case analysis," Journal of the Korean Society of Civil Engineers, vol. 33, no. 2, pp. 801-810, 2013.

[8] B. Kang, J. H. Lee, E. S. Chung, D. Kim, and Y. D. Kim, "A sensitivity analysis approach of multi-attribute decision making technique to rank flood mitigation projects," KSCE Journal of Civil Engineering, vol. 17, no. 6, pp. 1529-1539, 2013.

[9] H. S. Kim, G. J. Park, and S. D. Kim, "Assessment of flood vulnerability considering climate change and large-scale river restoration project," Journal of the Korean Society of Hazard Mitigation, vol. 12, no. 2, pp. 107-113, 2012.

[10] M. H. Lee, L. W. Jung, and D. H. Bae, "Korean flood vulnerability assessment on climate change," Journal of Korea Water Resources Association, vol. 44, no. 8, pp. 653-666, 2011.

[11] Y. A. Kwon, W. T. Kwon, K. O. Boo, and Y. Choi, "Future projections on subtropical climate regions over South Korea using," Journal of the Korean Geographic Society, vol. 42, no. 3, pp. 355-367, 2007.

[12] J. Y. Park, M. J. Park, S. R. Ahn, and S. J. Kim, "Watershed modeling for assessing climate change impact on stream water quality of Chungju Dam watershed," Journal of Korea Water Resources Association, vol. 42, no. 10, pp. 877-889, 2009.

[13] J. G. Arnold, Spatial scale variability in model development and parameterization [Ph.D. thesis], Purdue University, West Lafayette, Ind, USA, 1992.

[14] M. J. Muerth, B. Gauvin St-Denis, S. Ricard et al., "On the need for bias correction in regional climate scenarios to assess climate change impacts on river runoff," Hydrology and Earth System Sciences, vol. 17, no. 3, pp. 1189-1204, 2013.

[15] J. Alcamo, P. Döll, F. Kaspar, and S. Siebert, "Global change and global scenarios of water use and availability: an application of Water Cap 1.0," Report A9701, Center for Environmental System Research, University of Kassel, Kassel, Germany, 1997.

[16] H. A. Panofsy and G. W. Brire, Some Application of Statistics to Meteorology, Pennsylvania State University, University Park, Pennsylvania, Pa, USA, 1963.

[17] L. E. Hay and M. P. Clark, "Use of statistically and dynamically downscaled atmospheric model output for hydrologic simulations in three mountainous basins in the western United States," Journal of Hydrology, vol. 282, no. 1-4, pp. 56-75, 2003.

[18] H. J. Fowler, S. Blenkinsop, and C. Tebaldi, "Linking climate change modelling to impacts studies: recent advances in downscaling techniques for hydrological modelling," International Journal of Climatology, vol. 27, no. 12, pp. 1547-1578, 2007.

[19] J. Diaz-Nieto and R. L. Wilby, "A comparison of statistical downscaling and climate change factor methods: Impacts on low flows in the River Thames, United Kingdom," Climatic Change, vol. 69, no. 2-3, pp. 245-268, 2005.

[20] C. Prudhomme, S. Crooks, A. L. Kay, and N. Reynard, "Climate change and river flooding: part 1 classifying the sensitivity of British catchments," Climatic Change, vol. 119, no. 3-4, pp. 933948, 2013.

[21] T. Sato, F. Kimura, and A. Kitoh, "Projection of global warming onto regional precipitation over Mongolia using a regional climate model," Journal of Hydrology, vol. 333, no. 1, pp. 144-154, 2007.

[22] E. Tate, J. Sutcliffe, D. Conway, and F. Farquharson, "Water balance of Lake Victoria: update to 2000 and climate change modelling to 2100," Hydrological Sciences Journal, vol. 49, no. 4, pp. 563-574, 2004. 
[23] R. L. Wilby, J. Troni, Y. Biot et al., "A review of climate risk information for adaptation and development planning," International Journal of Climatology, vol. 29, no. 9, pp. 1193-1215, 2009.

[24] M. J. Themeßl, A. Gobiet, and A. Leuprecht, "Empiricalstatistical downscaling and error correction of daily precipitation from regional climate models," International Journal of Climatology, vol. 31, no. 10, pp. 1530-1544, 2011.

[25] L. Gudmundsson, J. B. Bremnes, J. E. Haugen, and T. E. Skaugen, "Technical note: downscaling RCM precipitation to the station scale using quantile mapping-a comparison of methods," Hydrology and Earth System Sciences Discussions, vol. 9, no. 9, pp. 6185-6201, 2012.

[26] D. Maraun, "Bias correction, quantile mapping, and downscaling: revisiting the inflation issue," Journal of Climate, vol. 26, no. 6, pp. 2137-2143, 2013.

[27] B. Thrasher, E. P. Maurer, C. McKellar, and P. B. Duffy, "Technical Note: bias correcting climate model simulated daily temperature extremes with quantile mapping," Hydrology and Earth System Sciences, vol. 16, no. 9, pp. 3309-3314, 2012.

[28] J. Chen, F. P. Brissette, D. Chaumont, and M. Braun, "Performance and uncertainty evaluation of empirical downscaling methods in quantifying the climate change impacts on hydrology over two North American river basins," Journal of Hydrology, vol. 479, pp. 200-214, 2013.

[29] F. S. Mpelasoka and F. H. S. Chiew, "Influence of rainfall scenario construction methods on runoff projections," Journal of Hydrometeorology, vol. 10, no. 5, pp. 1168-1183, 2009.

[30] J. Boé, L. Terray, F. Habets, and E. Martin, "Statistical and dynamical downscaling of the Seine basin climate for hydrometeorological studies," International Journal of Climatology, vol. 27, no. 12, pp. 1643-1655, 2007.

[31] T. Hashino, A. A. Bradley, and S. S. Schwartz, "Evaluation of bias-correction methods for ensemble streamflow volume forecasts," Hydrology and Earth System Sciences, vol. 11, no. 2, pp. 939-950, 2007.

[32] B. Kang and S. Moon, "Realtime streamflow prediction using quantitative precipitation model output," Journal of the Korean Society of Civil Engineers, vol. 30, no. 6b, pp. 579-587, 2010.

[33] L. R. Leung, A. F. Hamlet, D. P. Lettenmaier, and A. Kumar, "Simulations of the ENSO hydroclimate signals in the Pacific Northwest Columbia River Basin," Bulletin of the American Meteorological Society, vol. 80, no. 11, pp. 2313-2329, 1999.

[34] A. W. Wood, E. P. Maurer, A. Kumar, and D. P. Lettenmaier, "Long-range experimental hydrologic forecasting for the Eastern United States," Journal of Geophysical Research D: Atmospheres, vol. 107, no. 20, pp. 1-15, 2002.

[35] G. A. Grell, J. Dudhia, and D. R. Stauffer, A Description of the Fifth-Generation Penn State/NCAR Mesoscale Model (MM5), Mesoscale and Microscale Meteorology Division, 1994.

[36] T. Q. Murdock and D. L. Spottlehouse, "Selecting and using climate change scenarios for British Columbia," in Pacific Climate Impacts Consortium, pp. 1-27, University of Victoria, Victoria, BC, Canada, 2011.

[37] J. H. Lee and C. J. Kim, "A multi model assessment of the climate change effect on the drought severity-duration-frequency relationship," Hydrological Processes, vol. 27, no. 19, pp. 2800-2813, 2013.

[38] C. J. Kim, M. J. Park, and J. H. Lee, "Analysis of climate change impacts on the spatial and frequency patterns of drought using a potential drought hazard mapping approach," International Journal of Climatology, vol. 34, no. 1, pp. 61-80, 2014.
[39] S. J. Hong, B. S. Kim, and S. R. Ha, "Climate change impact assessment on Han River long term runoff in South Korea based on RCP climate change Scenario," Terrestrial Atmospheric and Oceanic Sciences, vol. 25, no. 5, pp. 689-701, 2014.

[40] Y. Seung-Hwan, C. Jin-Yong, L. Sang-Hyun, O. Yun-Gyeong, and Y. Dong Koun, "Climate change impacts on water storage requirements of an agricultural reservoir considering changes in land use and rice growing season in Korea," Agricultural Water Management, vol. 117, pp. 43-54, 2013.

[41] J. Kim, J. Choi, C. Choi, and S. Park, "Impacts of changes in climate and land use/land cover under IPCC RCP scenarios on streamflow in the Hoeya River Basin, Korea," Science of the Total Environment, vol. 452-453, pp. 181-195, 2013.

[42] T. Lee and C. Jeong, "Nonparametric statistical temporal downscaling of daily precipitation to hourly precipitation and implications for climate change scenarios," Journal of Hydrology, vol. 510, pp. 182-196, 2014.

[43] I. W. Jung, D. H. Bae, and B. J. Lee, "Possible change in Korean streamflow seasonality based on multi-model climate projections," Hydrological Processes, vol. 27, no. 7, pp. 1033-1045, 2013.

[44] J.-W. Lee and S.-Y. Hong, "Potential for added value to downscaled climate extremes over Korea by increased resolution of a regional climate model," Theoretical and Applied Climatology, vol. 117, no. 3-4, pp. 667-677, 2013.

[45] J. E. Nash and J. V. Sutcliffe, "River flow forecasting through conceptual models part I-a discussion of principles," Journal of Hydrology, vol. 10, no. 3, pp. 282-290, 1970.

[46] T. W. Chu and A. Shirmohammadi, "Evaluation of the SWAT model's hydrology component in the Piedmont physiographic region of Maryland," Transactions of the ASAE, vol. 47, no. 4, pp. 1057-1073, 2004.

[47] Y. C. Shin, J. D. Choi, K. J. Lim et al., "Pollutant load characteristics from a small mountainous agricultural watershed in the north Han river basin," Journal of the Korean Society of Agricultural Engineers, vol. 47, no. 6, pp. 83-92, 2005. 

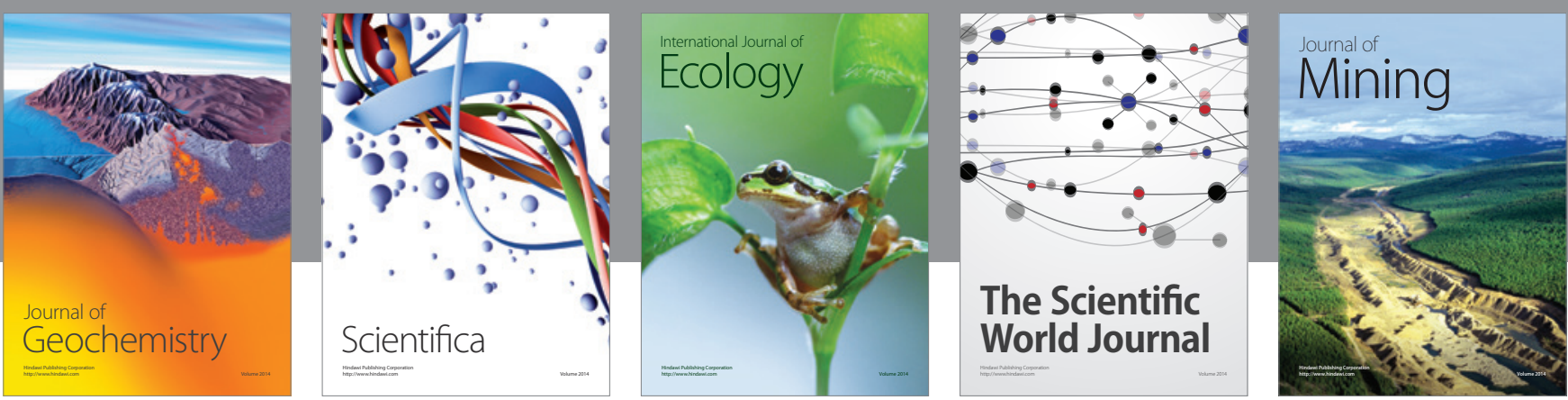

The Scientific World Journal
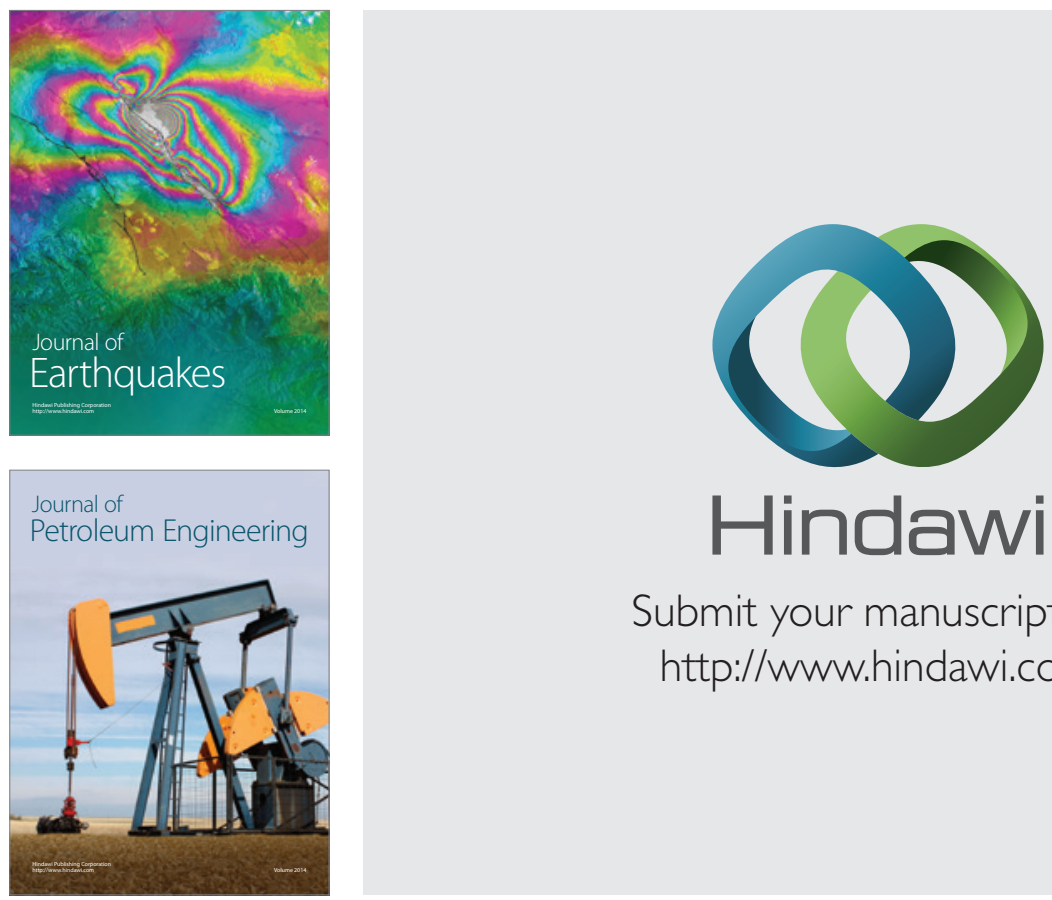

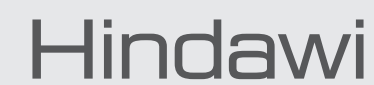

Submit your manuscripts at

http://www.hindawi.com
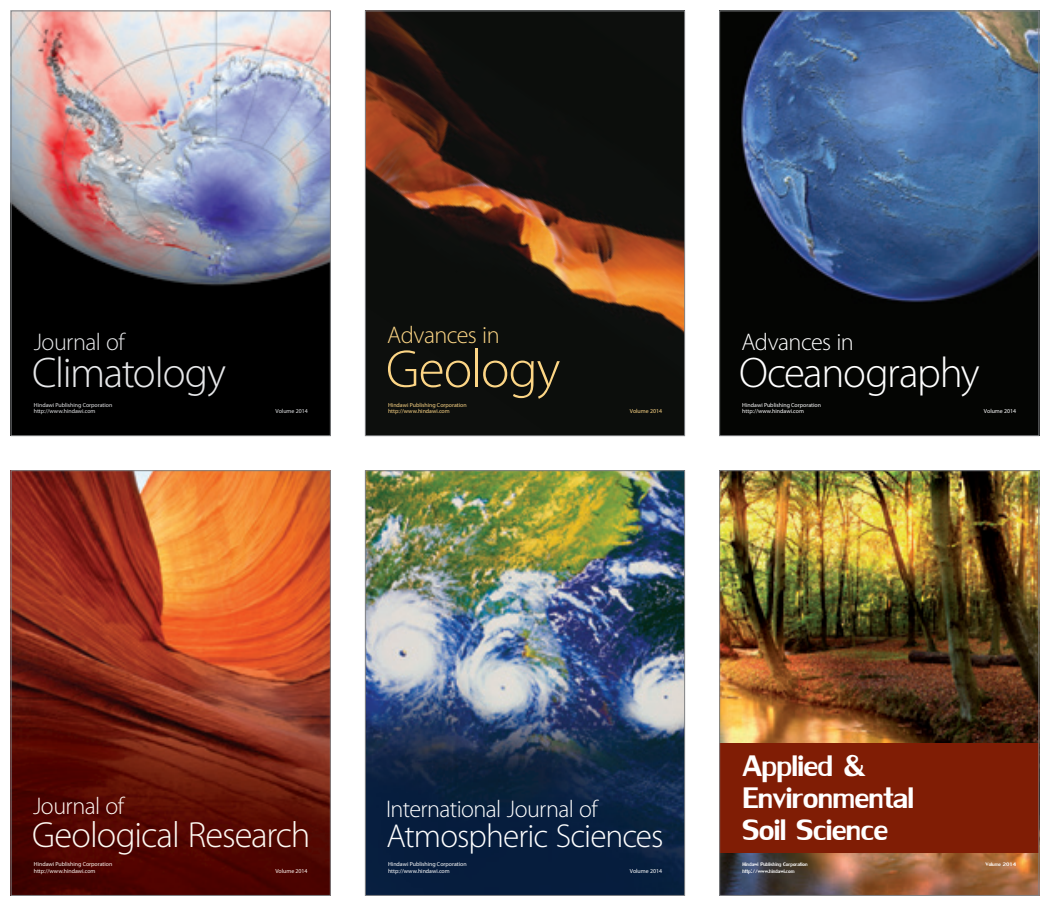
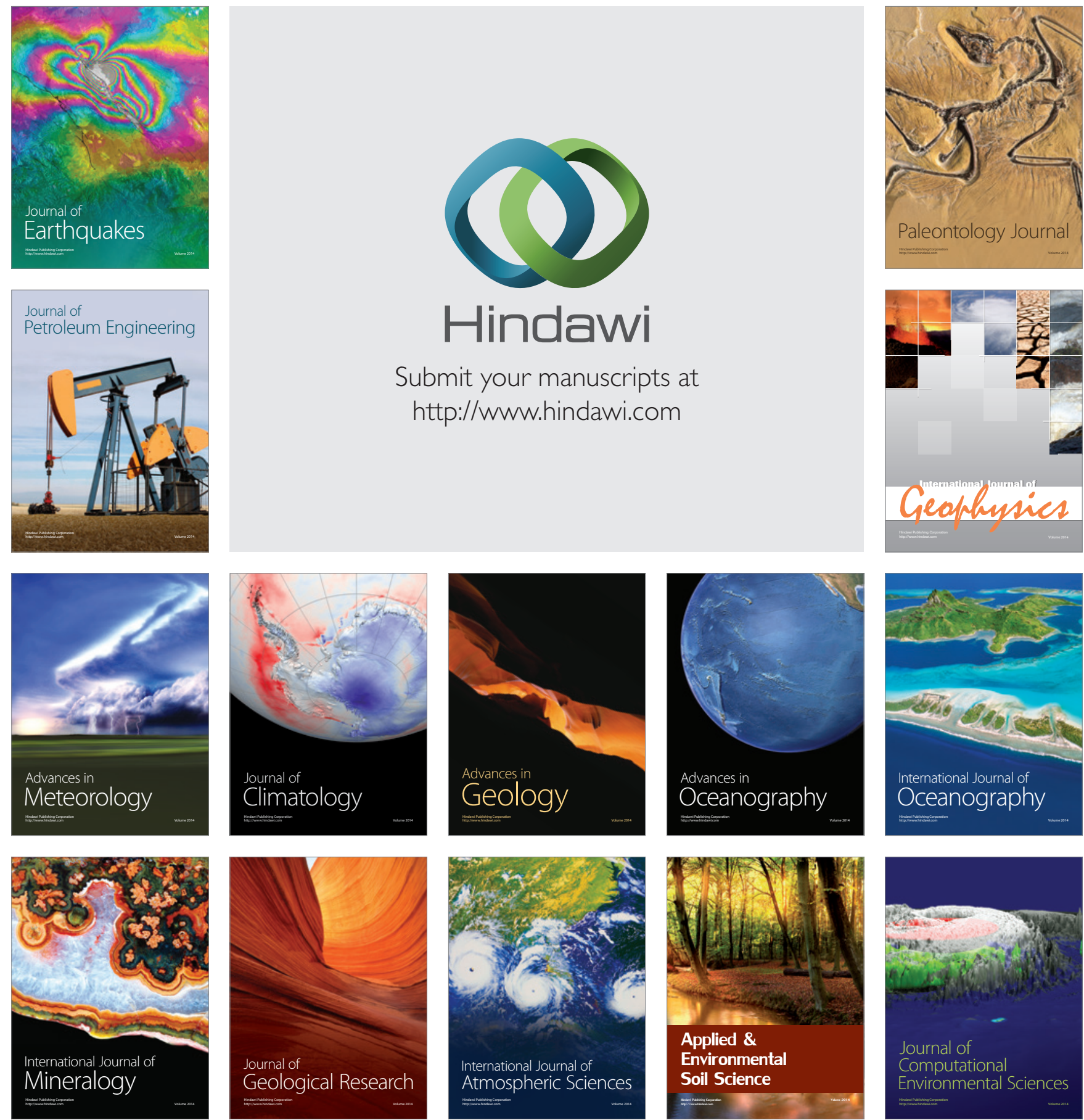